\title{
Significance of intraocular pressure measurement in systemic hypertension
}

\author{
BILLIE I. WILLIAMS AND J. G. LEDINGHAM \\ From the Nuffield Department of Medicine, John Radcliffe Hospital, Oxford
}

SUMmary In normotensive subjects no differences were found between morning and afternoon measurements of (i) mean level of intraocular pressure (IOP), (ii) variance of IOP, and (iii) rise of IOP associated with lying down. Conversely, in subjects with untreated hypertension (UH) morning values of (i), (ii), and (iii) were all significantly elevated. Within each group morning and afternoon levels of systolic blood pressure (BP) remained constant but in UH the morning variance of systolic BP was elevated in proportion to the degree of hypertension. This disparate elevation resulted in highly significant correlations between levels and variance of systolic BP and IOP in the morning. These correlations were weaker or absent in the afternoon, and in normotensive persons at both times. These observations may explain the tendency of retinal vein occlusion to occur in the morning. Their relationship to the vascular changes of hypertension pose a problem for future study.

In previous investigations of the haemodynamic changes occurring in association with the development of retinal vein occlusion certain differences were found between groups of control subjects and groups of subjects with a manifest retinal vein occlusion or with hypertension or diabetes - the 2 major systemic diseases associated with its development. All 3 groups of patients showed the following significant abnormalities: (1) a greater variance of systemic arterial pressure; (2) a greater variance of intraocular pressure in both eyes; and (3) a greater rise of intraocular pressure (in both eyes) after the subject had been lying down for 15 minutes. ${ }^{15}$ The above findings were derived from observations taken at different times of the day and on patients who had been selected irrespective of whether they were receiving treatment or not. It was not possible therefore to analyse any correlations between levels and variance of systemic and/or intraocular pressure, since in the case of patients with treated hypertension, for example, the systemic and possibly the intraocular pressure levels had been modified by therapy. Further, clinical evidence that retinal vein occlusion occurs predominantly in the morning demanded that any comparative studies be carried out at the same time of day. It was decided therefore to study a group of subjects with untreated hypertension and repeat

Correspondence to Dr B. I. Williams, 1 Park Square West, London NW1. previous intraocular and systemic measurements twice on each subject-i.e., in the morning and in the afternoon-following the same procedures on a group of control subjects for comparison.

As an arbitrary definition of hypertension the same criteria as in previous studies were used: a systolic pressure greater than $150 \mathrm{mmHg}$ or a diastolic pressure greater than $90 \mathrm{mmHg}$ on more than one occasion.

\section{Subjects and methods}

Two groups were examined: (1) 10 normotensive, healthy subjects, 6 men and 4 women; their ages ranged from 26 to 52 years, mean $34 \cdot 6$; (2) 13 subjects with hypertension, 4 men and 9 women; their ages ranged from 25 to 65 years, mean $43 \cdot 15$. There was no statistically significant difference in the ages of the 2 groups (unpaired $t$ test; DF $21 ; t=1 \cdot 63 ; \mathrm{p}>0.05$ ).

The studies were carried out in a quiet room with reasonably constant temperature and illumination. Measurements of intraocular pressure were made with the Alcon Applanation Pneumotonograph (Alcon Laboratories Inc.), which produces a permanent tracing of the intraocular pulse during the few seconds of applanation. With adequate corneal anaesthesia ( 1 drop of $0 \cdot 3 \%$ sodium oxybuprocaine every 15 minutes) the subject is unaware that the tonometer is touching the eye. Blood pressure measurements were recorded with the Dinamap 845 
Table 1 Intraocular pressure $(\mathrm{mmHg})$

\begin{tabular}{|c|c|c|c|c|}
\hline & & Control & Hypertension & $\begin{array}{l}\text { Hypertension } \\
\text { Control }\end{array}$ \\
\hline \multirow{3}{*}{$\overline{A M}$} & Mean level & $19 \cdot 1 \pm 1 \cdot 7$ & $21 \cdot 3 \pm 2 \cdot 4$ & $\mathrm{p}<0 .(0) 25$ \\
\hline & Postural risc & $3 \cdot 5 \pm 1 \cdot 5$ & $5 \cdot 5 \pm 3 \cdot()$ & $\mathrm{p}<0.01$ \\
\hline & Variance & 1.5 & $3 \cdot 1$ & $\mathrm{p}<0(0 \cdot()) 1$ \\
\hline \multirow[t]{3}{*}{ PM } & Mean level & $19 \cdot 1 \pm 3 \cdot()$ & $19 \cdot 9 \pm 2 \cdot 4$ & NS \\
\hline & Postural rise & $3 \cdot 1 \pm 1 \cdot 4$ & $3 \cdot 5 \pm 2 \cdot 1$ & NS \\
\hline & Variance & 1.4 & $2 \cdot 4$ & $\mathrm{p}<0 .(0) 1$ \\
\hline \multirow[t]{3}{*}{$\mathrm{AM} / \mathrm{PM}$} & 1 Mean Level & NS & $\mathrm{p}<0 .(0) 1$ & \\
\hline & Postural rise & NS & $p<0 .(0)$ & \\
\hline & Variance & NS & $\mathrm{p}<() \cdot(0) 5$ & \\
\hline
\end{tabular}

The residual variance within the group, after allowing for variation within individuals, is shown. Variances compared by Fisher's $F$ test. Mcan levels compared by paired t test (within groups), unpaired $t$ test between groups. NS= not significant.

noninvasive adult/paediatric vital signs monitor (Critikon).

Great attention was paid to the ease and comfort of the subjects by taking care to see that the fitting of the blood-pressure cuff, position of the limbs, and anaesthesia of the cornea were faultless. Details of the procedure were explained carefully, and trial measurements were made so that the subject was as relaxed as possible. Each subject was asked to sit quietly on a couch for 15 minutes, during which time a brief medical and family history was obtained and ophthalmoscopy performed. The anaesthetic drops were then instilled into the conjunctival sacs and the intraocular pressure measured in both eyes, the right eye being measured first. The tracings obtained were discarded, and 5 minutes later the measurements repeated. These tracings were recorded as the sitting values.

The subject was then asked to lie down from the sitting position, and the intraocular pressures were measured after 15 minutes had elapsed. These values were recorded as the supine values.

Following this the Dinamap cuff was applied to the subject's right arm and the blood pressure and heart rate measured and recorded automatically at 4minute intervals ( 7 readings). The cuff was then removed and the intraocular pressures in both eyes measured at similar intervals ( 7 readings).

The mean intraocular pressure at each time of observation was measured from the pneumotonograph tracing. The variance (mean sum of squares of differences from the mean) was used as a measure of the variability of intraocular and blood pressures. For each measured variable the variance was calculated, and within each group of subjects the residual variance, allowing for variability between individual subjects, was calculated by an analysis of variance. Variances were compared by Fisher's $F$ test. The whole procedure was carried out on each subject on 2 occasions: (1) beginning at $9.0 \mathrm{am},(2)$ beginning at $2.30 \mathrm{pm}$. Results are quoted as mean \pm 1 standard deviation. Differences between means or between variances are considered significant when $\mathrm{p}<0 \cdot 05$.

\section{Results}

\section{INTRAOCULAR PRESSURE}

Reference to Table 1 shows that in the morning mean level, postural rise, and variance of the group of subjects with untreated hypertension were all significantly greater than in the afternoon. These values were also significantly greater than both the morning and afternoon values found in the control group.

SYSTEMIC BLOOD PRESSURE (Table 2)

Compared with those in the control group both morning and afternoon mean levels of systolic and diastolic pressures were significantly greater in the hypertensive group. Within either group there was no significant difference between the morning and afternoon mean levels of systolic and diastolic pressure. Within the control group the variance of systolic pressure in the morning was significantly greater than in the afternoon, but there was no significant difference in the variance of the diastolic pressure. Within the hypertensive group there was a highly significant elevation of both systolic and diastolic pressure variance in the morning. The morning variance of the diastolic pressure was

Table 2 Blood pressure

\begin{tabular}{|c|c|c|c|c|c|c|c|}
\hline & & Control & & Hypertension & & Hyperten. & Control \\
\hline \multirow{3}{*}{ AM } & & SP & DP & SP & DP & & DP \\
\hline & Mean level & $122 \cdot 4 \pm(9 \cdot 4$ & $74 \cdot 4 \pm 5 \cdot 7$ & $155 \cdot 3 \pm 21 \cdot 6$ & $9(1) \cdot 1 \pm 10.9$ & $\mathrm{p}<0(0) \cdot(\mathrm{x}) 1$ & $\mathrm{p}<0(\mathbf{0} \cdot(\mathbf{x )}$ \\
\hline & Variance & $57 \cdot 2$ & $13 \cdot 0$ & 59.9 & $28 \cdot 5$ & NS & $p<0 .(0)$ \\
\hline \multirow[t]{2}{*}{ PM } & Mean level & $124 \cdot 8 \pm 9 \cdot 1$ & $72 \cdot 8 \pm 5 \cdot 9$ & $154 \cdot 1 \pm 23 \cdot 6$ & $87 \cdot 1 \pm 12 \cdot 1$ & $\mathrm{p}<0(1) \cdot(1) 25$ & $\mathrm{p}<0(0.0(0)$ \\
\hline & Variance & $37 \cdot 7$ & $12 \cdot 9$ & $28 \cdot 7$ & $15 \cdot 3$ & NS & NS \\
\hline \multirow[t]{2}{*}{$\mathrm{AM} / \mathrm{PM}$} & Meian level & NS & NS & NS & NS & & \\
\hline & Variance & $p<0.015$ & NS & $\mathrm{p}<(0) \cdot(\mathbf{)}) \mid$ & $\mathrm{p}<0.0(005$ & & \\
\hline
\end{tabular}

Statistical references as in Table $1 . S P=$ systolic pressure: $D P=$ diastolic pressure. 
Table 3 Blood pressure and intraocular pressure correlations

\begin{tabular}{|c|c|c|c|c|c|c|c|c|}
\hline & \multicolumn{4}{|c|}{ Control } & \multicolumn{4}{|c|}{ Hypertension } \\
\hline & $\mathrm{n}$ & $\begin{array}{l}\mathrm{SP} \\
\mathrm{p}\end{array}$ & $\begin{array}{l}\text { DO } \\
\mathrm{p}\end{array}$ & $\begin{array}{l}\mathrm{HR} \\
\mathrm{p}\end{array}$ & $\mathrm{n}$ & $\begin{array}{l}\text { SP } \\
\mathrm{p}\end{array}$ & $\begin{array}{l}\mathrm{DP} \\
\mathrm{p}\end{array}$ & $\begin{array}{l}\text { HR } \\
p\end{array}$ \\
\hline \multicolumn{9}{|l|}{$\mathrm{AM}$} \\
\hline Level/variance & 10 & NS & NS & NS & 13 & $<0 .(0) 1$ & NS & NS \\
\hline Level/IOP level & 20) & NS & NS & NS & 25 & NS & NS & NS \\
\hline Level/IOP variance & 20) & NS & NS & NS & 25 & $<0 .(0) 1$ & $<(0 \cdot 05$ & NS \\
\hline Variance/IOP variance & 20) & NS & NS & NS & 25 & $<0 \cdot(0) 1$ & NS & NS \\
\hline Variance/IOP level & 20) & NS & NS & NS & 25 & $<0 \cdot(0)$ & NS & NS \\
\hline IOP Ievel/IOP variance & 20 & & $\mathrm{p}<0) \cdot(12$ & & 25 & & $\mathrm{p}<0.05$ & \\
\hline PM & & $\mathrm{p}$ & $\mathrm{p}$ & $\mathrm{p}$ & $\mathrm{n}$ & $\mathrm{p}$ & $\mathrm{p}$ & $\mathrm{p}$ \\
\hline Level/variance & 10 & NS & NS & NS & 13 & NS & NS & NS \\
\hline Level/IOP level & 10 & NS & NS & $<0 \cdot(1)$ & 25 & $<0) \cdot(05$ & NS & NS \\
\hline Level/IOP variance & 20 & NS & NS & NS & 25 & NS & NS & NS \\
\hline Variance/ IOP variance & 20 & NS & NS & $<() \cdot(0)$ & 25 & NS & NS & NS \\
\hline Variance/IOP level & 20 & NS & NS & $<() \cdot(0)$ & 25 & NS & NS & NS \\
\hline IOP Icvel/IOP variance & 20 & & NS & & 25 & & NS & \\
\hline
\end{tabular}

significantly greater in the hypertensive group than in the control group. There was no significant difference between the afternoon variances of systolic or diastolic pressure in the 2 groups.

CORRELATIONS BETWEEN SYSTEMIC PRESSURE, HEART RATE, AND INTRAOCULAR PRESSURE

From Table 3 it can be seen that in the control group there were no significant relationships between any of the systemic or intraocular pressure mean levels or variances. However, in the afternoon both heart rate level and variance were related to intraocular pressure level and variance. In contrast, in the hypertensive group, highly significant correlations were found between systolic and intraocular pressure levels and variance in the morning.

Table 4 Hypertensive subjects in descending order of morning systolic pressure variance

\begin{tabular}{|c|c|c|c|}
\hline Case & $S P$ & SP variance & Fundal appearance \\
\hline \multicolumn{4}{|c|}{ Hypertensive group } \\
\hline 1 & $214 \cdot 6$ & $169 \cdot 5$ & Right CRAO, A, V, A/V \\
\hline 2 & $167 \cdot 5$ & $109 \cdot 6$ & $\mathrm{~V}, \mathrm{~A} / \mathrm{V}$ \\
\hline 3 & $157 \cdot 7$ & 86.9 & V \\
\hline 4 & $158 \cdot 4$ & $72 \cdot 9$ & $\mathrm{~V}, \mathrm{~A} / \mathrm{V}$ \\
\hline 5 & $156 \cdot()$ & $70 \cdot 3$ & Normal \\
\hline 6 & $174 \cdot 4$ & $69 \cdot 6$ & Right pate disc, $A, V, A / V$ \\
\hline 7 & $147 \cdot 1$ & $41 \cdot 1$ & $\mathrm{~V}, \mathrm{~A} / \mathrm{V}$ \\
\hline 8 & $132 \cdot 3$ & $39 \cdot 2$ & Normal \\
\hline 9 & $133 \cdot 9$ & $26 \cdot 9$ & Normal \\
\hline 10 & $148 \cdot 3$ & $26 \cdot 5$ & Normal \\
\hline 11 & 14()$\cdot 0$ & $26 \cdot 3$ & Normal \\
\hline 12 & $143 \cdot 5$ & $24 \cdot 9$ & Normal \\
\hline 13 & $145 \cdot 3$ & $10 \cdot 9$ & Normal \\
\hline \multicolumn{4}{|c|}{ Control group } \\
\hline & $122 \cdot 4$ & $57 \cdot 2$ & Normal \\
\hline
\end{tabular}

$\mathrm{SP}=$ systolic pressurc. $\mathrm{CRAO}=$ central retinal artery occlusion. $\mathrm{A}=$ thin arteries. $V=$ fat veins. $A / V=$ arteriovenous sign.
In both the hypertensive and control groups there was a significant relationship between the level and variance of intraocular pressure in the morning but not in the afternoon.

\section{OPHTHALMOSCOPY}

Table 4 shows a list of the hypertensive subjects arranged in descending order of morning systolic pressure variance, followed by the mean value for the whole group of control subjects.

Figs. 1 and 2 show the individual relationships between mean level of systolic pressure and variance of systolic pressure in the morning (Fig. 1) and afternoon (Fig. 2). Fig. 1 shows 16 subjects with hypertension, 3 subjects who were examined only in the morning being added to the original 13 cases. Fig. 2 shows 17 subjects with hypertension, 4 subjects who were examined only in the afternoon being added. (The 'added' cases were submitted to exactly the same procedure as the other subjects and formed part of the study as planned originally. These subjects were able to attend for only one session - for example, morning or afternoon for various reasons. Some simply did not turn up for the study, while in other cases hypotensive therapy was considered advisable by their medical practitioner before the second study could take place.)

When the group of subjects selected as hypertensive is considered,

$$
\begin{aligned}
& n=13, R=() \cdot 91, p<0 \cdot()(01 . \\
& n=16, R=() \cdot 83, p<0) \cdot(x) 1 .
\end{aligned}
$$

and the $y$ intercept represents a systolic pressure level of $134.0 \mathrm{mmHg}(\mathrm{n}=16), 129.0 \mathrm{mmHg}(\mathrm{n}=13)$. That is, for these subjects a systolic blood pressure level of approximately $132 \mathrm{mmHg}$ represents the lowest level at which the relationship between level and variance begins to be apparent. 


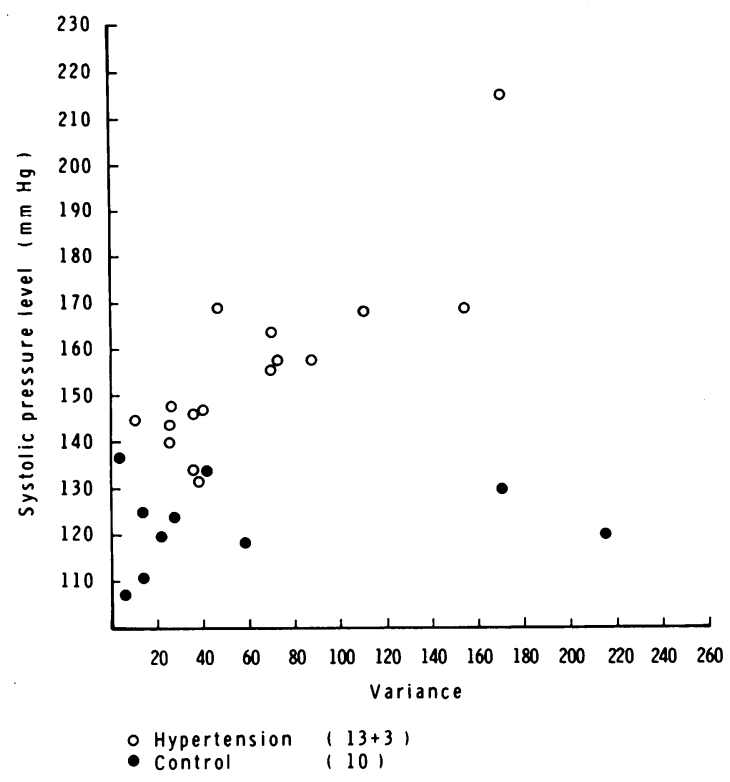

Fig. 1 Morning. Systolic pressure level versus variance.

The control group shows no correlation:

$$
n=10, R=0 \cdot(1) \text {, NS. }
$$

Reference to Fig. 2 shows that there is no significant relationship between afternoon level and variance of systolic pressure, when the total population is considered:

$$
\begin{aligned}
& n=23, R=0 \cdot(0) 1, N S . \\
& n=26, R=0 \cdot(0), N S .
\end{aligned}
$$

or when the hypertension group is considered,

$$
\begin{aligned}
& n=13, R=0 \cdot(13, N S . \\
& n=17, R=0 \cdot(17, \text { NS. }
\end{aligned}
$$

This loss of relationship is a result of the striking reduction in variance shown by the subjects with hypertension in the afternoon. Likewise, no correlation exists in the control group:

$$
n=10, R=() \cdot(0), N S \text {. }
$$

\section{Discussion}

These results indicate a difference between the haemodynamic behaviour of normotensive and hypertensive subjects which is strikingly evident in the morning. In view of the modest level of systemic hypertension in the group examined these results are remarkable. The one incongruous finding is the absence of a significant increase in the morning systolic pressure variance in the hypertensive group, since in previous studies elevation of blood pressure variance was most marked for systolic pressure in groups of subjects with retinal vein occlusion, hypertension, or diabetes. ${ }^{5}$ Further investigation of

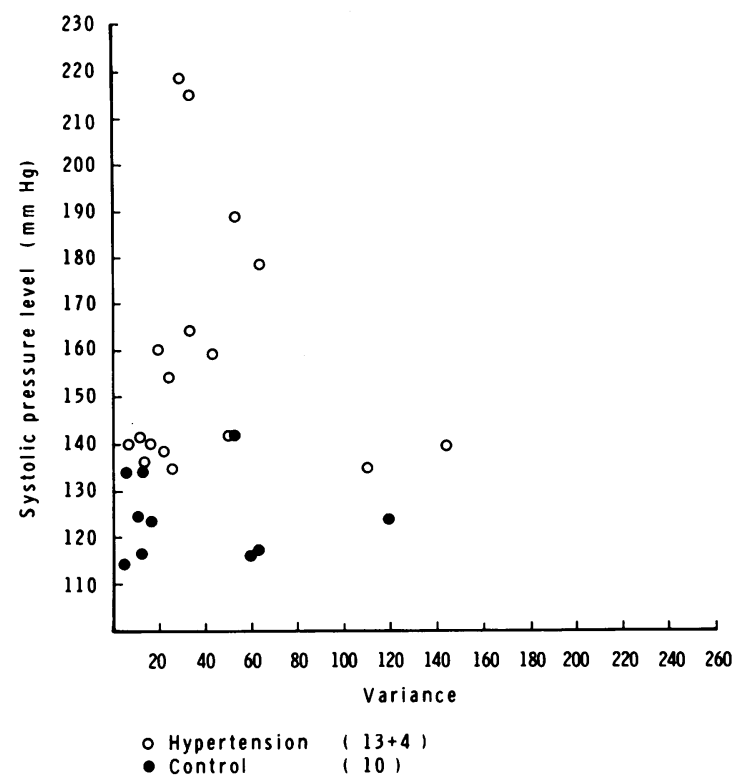

Fig. 2 Afternoon. Systolic pressure level versus variance.

this apparently surprising finding shows that it is due to the high proportion of subjects in the current series with relatively low mean levels of systolic pressure, resulting in a mean level for the group of about $155 \mathrm{mmHg}$.

Tables $5 \mathrm{a}$ and $5 \mathrm{~b}$ show the results of the division of the groups of subjects into subgroups according to systolic pressure. Each group was divided into 2 subgroups, the first containing the 6 subjects with the highest and the second the 7 subjects with the lowest pressures. These subgroups were then further subdivided as shown. In this way it was possible to demonstrate that, in the smaller number of subjects with mean levels higher than that for the whole group, variance was as had been expected, that is, significantly elevated. In contrast, similar subdivision of the group of control subjects shows a quite different pattern, with no evidence that variance and pressure are related at these lower levels of systemic pressure.

It seems unlikely that the differences in correlation between the 2 groups in the morning and afternoon are absolute. It may be that at higher levels of systemic arterial pressure the afternoon variables would become significantly related.

It is evident that the morning levels of variance of systolic blood pressure increase pro rata with increase of mean level of pressure, although the mean levels of pressure are remarkably constant morning and afternoon. Variability cannot therefore be a function of mean level but rather the measurement of a changing haemodynamic situation, the mechanism underlying 
Table 5a Morning. Systolic blood pressure: subgroups

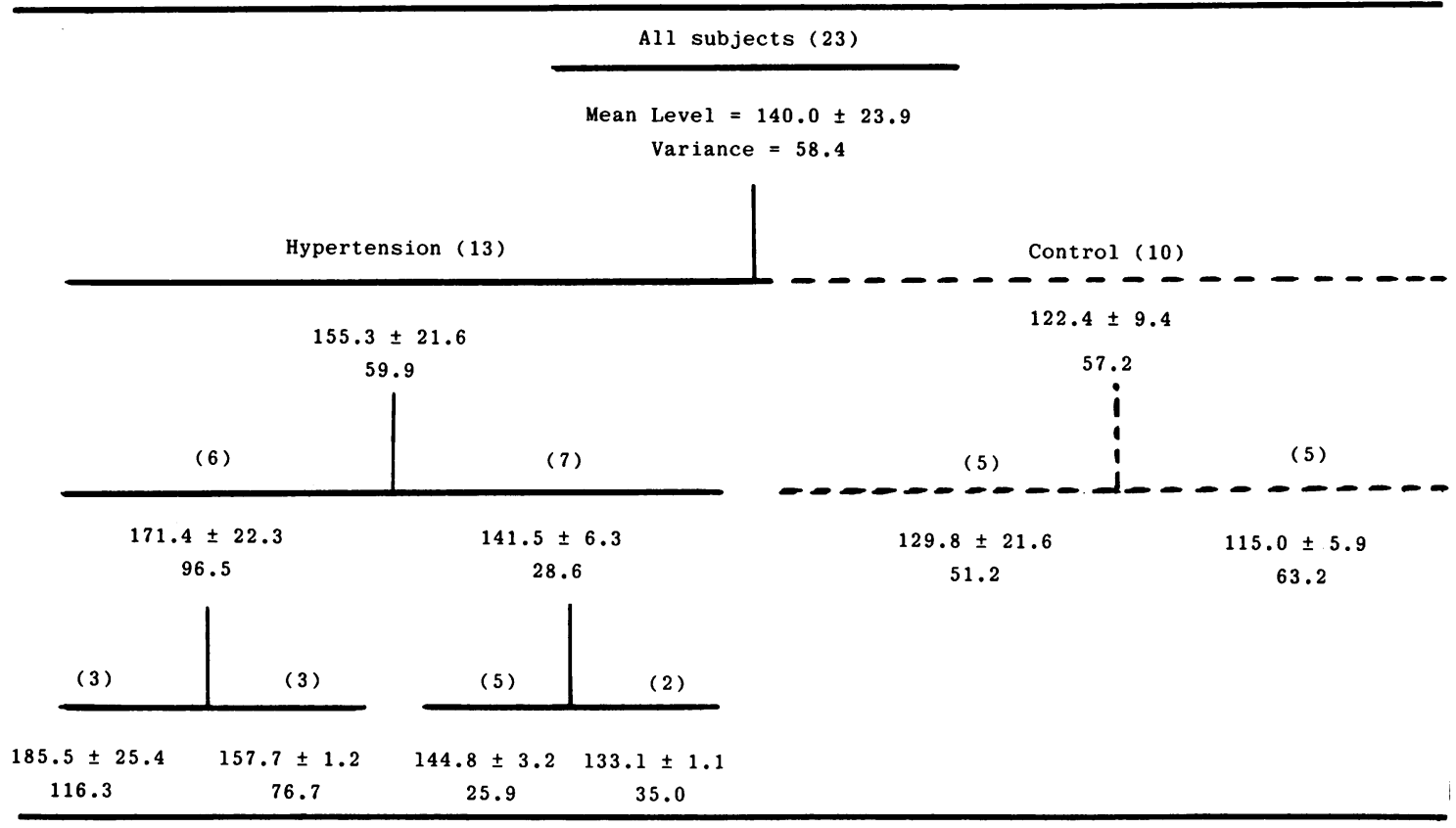

Table 5b Afternoon. Systolic blood pressure: subgroups

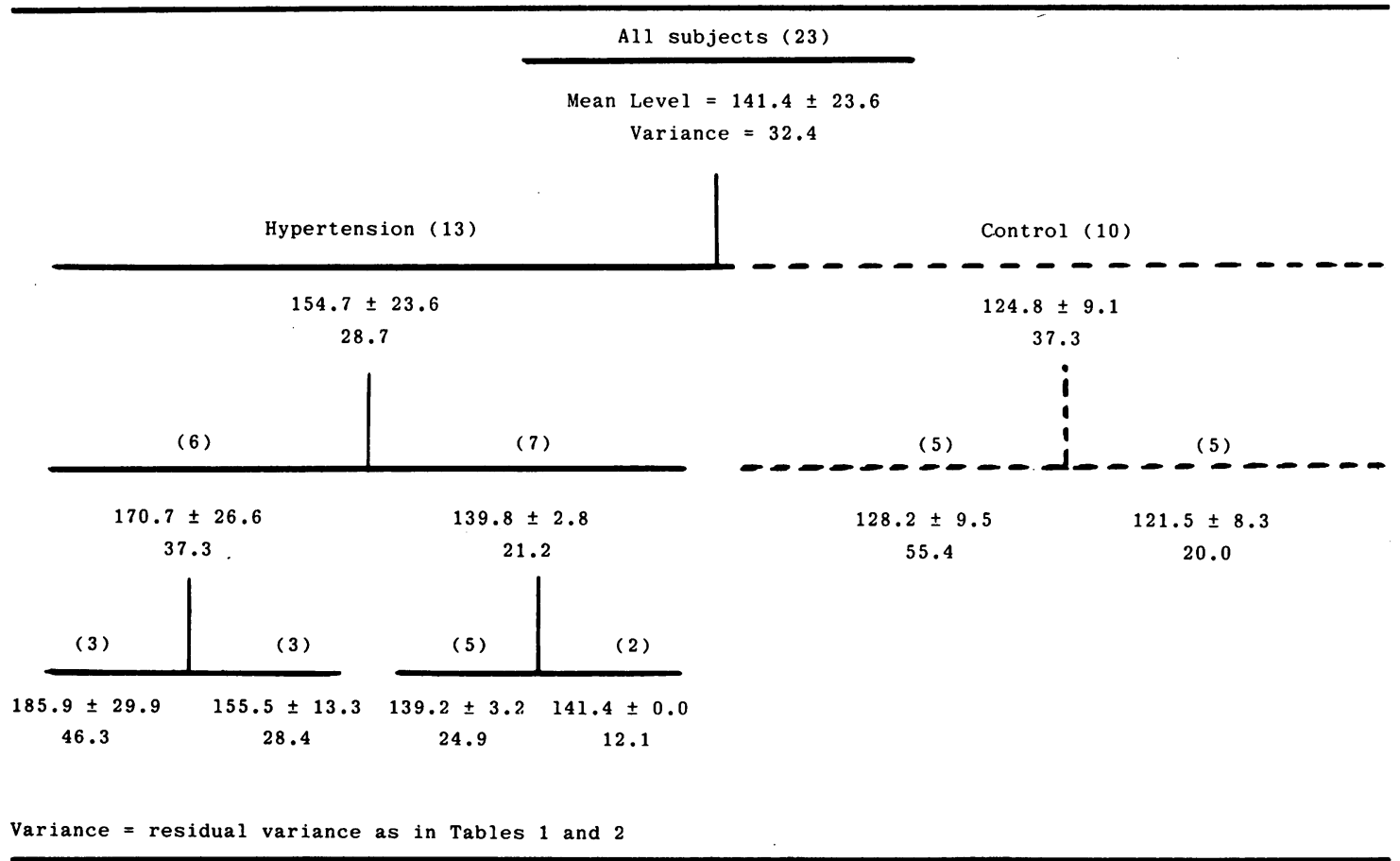

Variance $=$ residual variance as in Tables 1 and 2. 
which is yet to be determined. One would expect the nature of this difference and its aetiology to have significance for an understanding of the development of retinal vein occlusion since (i) this lesion very commonly presents in the morning; (ii) subjects with retinal vein occlusion have a significantly raised level of variance of blood pressure; (iii) subjects with hypertension and diabetes (the 2 diseases most commonly associated with retinal vein occlusion) have a significantly raised level of variance of blood pressure. But these systemic haemodynamic changes are closely mirrored in those that have been found in the intraocular circulation, where vascular changes in the retinal vessels and the development of sequelae such as retinal vein occlusion can be observed in the clinical situation.

The intraocular abnormalities found in subjects with hypertension are multiple:

(i) The morning mean level of intraocular pressure is significantly elevated when compared with the afternoon and control levels. This substantiates the results of our previous studies, which were carried out at various times of the day on groups of treated subjects with retinal vein occlusion, diabetes, and hypertension. Mean levels of intraocular pressure were found to be higher in all 3 groups when compared with control subjects, namely, $16 \cdot 9 \pm 2 \cdot 5$ (control); $20 \cdot 1 \pm 3 \cdot 4$ (diabetes); $18 \cdot 3 \pm 4 \cdot 1 \quad$ (retinal vein occlusion); $17 \cdot 5 \pm 3 \cdot 0$ (hypertension) $\mathrm{mmHg}$. The mean level in diabetes is significantly higher than the mean level in controls $(t=3 \cdot 39, \mathrm{DF}=38, \mathrm{p}<0 \cdot 01)$ but the mean levels in the hypertensive and venous obstruction groups are not. (These results, from studies previously reported, ${ }^{5}$ were not included in that abbreviated paper.) The present study on subjects with untreated hypertension shows that a significantly elevated level of pressure does exist, but only with respect to morning values.

(ii) The morning variance of intraocular pressure is significantly elevated.

(iii) The ability to maintain a constant level of intraocular pressure with change of posture is impaired in the morning as is shown by the abnormal rise occurring with change from the sitting to lying position.

That these abnormalities are present in subjects with systemic changes such as have been discussed opens up the possibility of examining the haemodynamic pathology of hypertension through a study of changes observed in the eye.

There is much to suggest that the variations in intraocular pressure level found in subjects with established systemic changes (of mean level and variance) are the result of changes in the intravascular volume of the eye. As a result of these and previous studies we have noted that levels of variance of intra- ocular pressure are reduced in subjects in whom one might expect a reduced input of blood into the globe-for example, marked arterial disease. Reduction of blood supply, associated with frank retinal artery occlusion, is typically associated with a lower level of variance in the affected eye than that found in the unaffected one. For instance, one of our patients who was found to have an arterial occlusion in one eye had a variance of 0.58 in this eye and 4.33 in the unaffected one. (We excluded this affected eye from our analyses-hence $n=25$ for 13 subjects.) A second subject, in whom the variance was 0.91 in one eye and 2.16 in the other, had been described as having 'a pale disc and thin arteries' in the ophthalmoscopic examination of this eye (Table 4 , cases 1 and 6 ).

We have also noted that subjects with retinal arterial lesions do not show the typically abnormal rise of intraocular pressure on lying down. Very often this rise is absent and in some cases the pressure has been noted to fall 1 or $2 \mathrm{mmHg}$. And, finally, the loss of blood from the vessels, associated with the onset of a major retinal vein occlusion results characteristically in a drop in the level of intraocular pressure in the affected eye. ' "Conversely, the high levels of variance seen par excellence in hypertensive subjects who have suffered a retinal vein occlusion and in whom retinal arterial attenuation is not marked, are associated with 2 predominant signs: the presence of fat retinal veins and a great increase of connective tissue at the arteriovenous crossings, resulting in the appearance of 'nipping' of the veins.

It is hoped that further studies to elucidate the relationship between these changes and the haemodynamic results described above may further our understanding of the vascular pathology associated with systemic hypertension.

Dr Billic Williams wishes to thank the Leverhulme Trustees for their generous grant which enabled this work to be carricd out.

\section{References}

1 Williams BI, Peart WS. Effect of posture on the intraocular pressure of patients with retinal vein obstruction. BrJ Ophthalmol 1978: 62: 688-93.

2 Williams BI, Peart WS. Retinal vein obstruction and intraocular pressure: abnormal postural response independent of facility of outflow. BrJ Ophthalmol 1979; 63: 805-7.

3 Williams BI, Peart WS. Letley E. Abnormal intraocular pressure control in systemic hypertension and diabetes mellitus. Br J Ophthalmol 1980); 64: 845-51.

4 Anonymous. Postural response of intraocular pressure in vascular discase (Editorial). Lancet 1981; i: 314.

5 Williams BI, Gordon D. Peart WS. Abnormal variability of intraocular pressure and systemic arterial blood pressure in diabetes. hypertension, and retinal venous occlusion. Preliminary communication. Lancet 1981; ii: 1255-7.

6 Moore JF. Retinal venous thrombosis. Br J Ophthalmol 1924; (monograph, suppl 2). 